\title{
Virological surveillance and antiviral resistance of human influenza virus in Argentina, 2005-2008
}

\author{
Andrea Pontoriero, ${ }^{1}$ Elsa Baumeister, ${ }^{1}$ Ana M. Campos, ${ }^{1}$ \\ and Vilma L. Savy ${ }^{1}$
}

Suggested citation

Pontoriero A, Baumeister E, Campos AM, Savy VL. Virological surveillance and antiviral resistance of human influenza virus in Argentina, 2005-2008. Rev Panam Salud Publica. 2011;30(6):634-40.

ABSTRACT Objective. To describe the virological characteristics of the influenza strains circulating in Argentina in 2005-2008 and to assess the prevalence of antiviral resistance.

Methods. On the basis of their geographical spread and prevalence, influenza $A$ and $B$ isolates grown in Madin-Darby canine kidney cells were selected after antigenic and genomic characterization to be analyzed for antiviral resistance by enzymatic assay and pyrosequencing. Amantadine susceptibility was evaluated by pyrosequencing for known resistance markers on 45 strains of influenza A. Susceptibility to oseltamivir and zanamivir was evaluated by enzymatic assay of 67 influenza A and 46 influenza B strains, some of which were further analyzed by sequencing the neuraminidase gene.

Results. Resistance to amantadine was observed only on A(H3N2) strains (29/33); all of them carried the mutation S31N in their M2 sequence. Oseltamivir resistance was observed in $12(34.3 \%)$ of the 35 A(H1N1) strains from 2008; all of them carried the mutation H275Y in their neuraminidase sequence. All these viruses remained sensitive to zanamivir.

Conclusions. This study describes a high incidence of amantadine-resistant influenza A(H3N2) viruses since 2006 and an unprecedented increase in oseltamivir resistance detected only in influenza $A(H 1 N 1)$ viruses isolated in 2008. Influenza $A$ and B viruses were more sensitive to oseltamivir than to zanamivir, and influenza $A$ viruses were more sensitive to both neuraminidase inhibitors than the influenza $B$ viruses. The national data generated and analyzed in this study may help increase knowledge about influenza antiviral drug resistance, which is a problem of global concern.

Key words Influenza, human; influenza A virus; drug resistance, viral; antiviral agents; Argentina.

Influenza is an infection of the upper respiratory tract that causes significant morbidity and mortality; its economical impact is estimated to run into billions of dollars worldwide (1). Identification

\footnotetext{
Administración Nacional de Laboratorios e Institutos de Salud "Dr. Carlos G. Malbrán," Instituto Nacional de Enfermedades Infecciosas, Departamento Virología, Buenos Aires, Argentina. Send correspondence to: Andrea Pontoriero, aponto@anlis.gov.ar
}

and characterization of circulating influenza viruses are essential for detecting the emergence of antigenic drift variants causing influenza epidemics and novel A subtypes with pandemic potential (2). Influenza surveillance also provides a basis for selecting the virus strains to be included in annual formulation of influenza vaccines $(3,4)$.

Although vaccination provides the primary means for protection from influenza virus infection, antiviral drugs provide a valuable addition to the available options used to control the virus. Two classes of specific anti-influenza drugs have been developed to date: amantadine and rimantadine, the adamantanes developed in the early 1960s (5) and targeted against the M2 proton channel of influenza A viruses (6), and zanamivir and oseltamivir, more recently developed inhibitors of the viral neuraminidase (7). The frequency of resistance to amantadine and rimantadine 
among circulating seasonal influenza A viruses has increased dramatically over the past few years (8). A previous report showed the emergence of amantadineresistant influenza $\mathrm{A}(\mathrm{H} 3 \mathrm{~N} 2)$ viruses in Argentina in 2006 and its circulation was still detected in 2007 (9).

A sustained antiviral susceptibility surveillance of influenza viruses in Europe revealed the emergence of seasonal influenza $\mathrm{A}(\mathrm{H} 1 \mathrm{~N} 1)$ viruses naturally resistant to the neuraminidase inhibitor oseltamivir (10), which is the most widely used antiviral drug for influenza and is a potent inhibitor of influenza virus neuraminidase activity (11). The viruses carried a specific histidine-to-tyrosine mutation at position 274 (H274Y; H275Y in the N1 numbering system) in the neuraminidase protein that confers a high-level resistance to oseltamivir (12). Data produced by the EISS/VIRGIL network until February 2009 showed that 97\% of the European isolates tested were resistant to oseltamivir but retained sensitivity to zanamivir, amantadine, and rimantadine (13). Before emergence of the novel H1N1 swine-origin influenza A virus, neuraminidase inhibitors were sporadically used to treat seasonal influenza in Argentina. Available data related to resistance to neuraminidase inhibitors in South America are poor. The aims of this study were to describe the virological characteristics of a subset of influenza A and B strains circulating in Argentina in the period 2005-2008 and to monitor the susceptibility to antiviral drugs.

\section{MATERIALS AND METHODS}

This work consists of an observational study based on influenza virological strain surveillance data carried out by antigenic analyses of the circulating strains integrated with the monitoring of susceptibility to antiviral drugs.

\section{Specimen collection}

Weekly influenza surveillance is conducted routinely by Instituto Nacional de Enfermedades Infecciosas, Administración Nacional de Laboratorios e Institutos de Salud "Dr. Carlos G. Malbran," a Pan American Health Organization/ World Health Organization National Influenza Center, through the National Influenza and Respiratory Viruses Laboratory Network, which also participates in the World Health Organization Global Influenza Surveillance Network.

The sampling effort of this network is constant year round and is part of the influenza national surveillance system of the Argentinean Ministry of Health.

The national network consists of 24 laboratories distributed throughout the country that routinely study 24000 31000 respiratory samples per year for diagnostic testing. Nasopharyngeal aspirates and throat or nasal swabs from pediatric and adult outpatients and inpatients with acute respiratory infection are collected and examined by immunofluorescence assay for diagnosis of influenza A, influenza B, and other respiratory viruses, including respiratory syncytial virus, adenovirus, and parainfluenza virus. Between 800 and 1000 influenza A- or B-positive samples per year are submitted to the National Influenza Center for further characterization.

\section{Virus propagation, subtype determination, and antigenic characterization}

Madin-Darby canine kidney cells were used to isolate viruses from clinical samples. Specimens for isolation were selected taking into account the collecting date, the specimen preservation conditions, and the geographical location in order to be able to obtain isolates with different characteristics throughout the study period. Virus isolates were serotyped by hemagglutination inhibition assay or indirect immunofluorescence assay using the World Health Organization influenza reagent kit provided annually by the Centers for Disease Control and Prevention (Atlanta, Georgia, United States of America). Antigens were characterized by hemagglutination inhibition test with postinfection ferret antisera and turkey red blood cells.

\section{Antiviral resistance tests}

Unlike other countries, such as the United States and European countries, routine surveillance for detection of antiviral resistance in influenza viruses has not been locally established in South American countries. For a better approach to the situation in Argentina, it was considered important to monitor for the emergence of antiviral resistance in addition to virological surveillance. The antiviral assays consist of measur- ing neuraminidase enzyme activity in the presence of oseltamivir and zanamivir to determine the drug sensitivity of the viral enzyme. Sequences of the ion channel region of the M2 gene and the neuraminidase gene were also analyzed to detect mutations associated with reduced susceptibility or drug resistance.

Viral strains tested for neuraminidase susceptibility. From the total influenza A(H1N1) (478), influenza A(H3N2) (609), and influenza B (342) viruses isolated between 2005 and 2008, a subset of 113 were selected for analysis of neuraminidase susceptibility: 35 influenza $\mathrm{A}(\mathrm{H} 1 \mathrm{~N} 1), 32$ influenza $\mathrm{A}(\mathrm{H} 3 \mathrm{~N} 2)$, and 46 influenza B viruses. Strains selected for this study were collected throughout the study period and represent the types and subtypes circulating in each particular season in different parts of the country: Catamarca, Chaco, Salta, Tucuman, Santa Fe, Mendoza, Buenos Aires, Chubut, and Neuquen provinces. The total number of isolates evaluated for antiviral resistance per year based on influenza type and subtype is shown in Table 1.

Antiviral drugs. Zanamivir was provided by GlaxoSmithKline (London, United Kingdom). Oseltamivir carboxylate (GS4071), the active compound of the ethyl ester prodrug oseltamivir phosphate (GS4104), was supplied by Roche Products Ltd. (Burgess Hill, United Kingdom).

Neuraminidase inhibition assays. To study neuraminidase susceptibility, enzymatic assays were performed at the Health Protection Agency (London, United Kingdom) to determine the drug concentration that provides $50 \%$ inhibition $\left(\mathrm{IC}_{50}\right)$ using the fluorescent substrate methylumbelliferyl $N$-acetylneuraminic acid (Sigma Chemical Co., St. Louis, Missouri, United States) according to previ-

TABLE 1. Influenza A and B isolates tested for oseltamivir resistance for each influenza type and subtype, Argentina, 2005-2008

\begin{tabular}{|c|c|c|c|c|}
\hline \multirow[b]{2}{*}{ Year } & \multicolumn{2}{|c|}{ Influenza A } & \multirow[b]{2}{*}{ Influenza B } & \multirow[b]{2}{*}{ Total } \\
\hline & H3N2 & $\mathrm{H} 1 \mathrm{~N} 1$ & & \\
\hline 2005 & 4 & 0 & 6 & 10 \\
\hline 2006 & 3 & 4 & 5 & 12 \\
\hline 2007 & 24 & 0 & 0 & 24 \\
\hline 2008 & 1 & 31 & 35 & 67 \\
\hline Total & 32 & 35 & 46 & 113 \\
\hline
\end{tabular}


ously described methods (14). $\mathrm{IC}_{50}$ values of antiviral drugs were determined on the basis of the drug concentration at which there was a $50 \%$ reduction in fluorescence; results were reported as the mean of duplicate values. Baseline sensitivity of N1, N2, and B viruses was calculated from the $\mathrm{IC}_{50}$ values of nonoutlier strains.

Statistical analysis. $\log _{10}$-transformed $\mathrm{IC}_{50}$ values for a given subtype were analyzed to highlight potentially resistant isolates as outliers. Robust estimations of the standard deviation $(1.48 \times$ median absolute deviation) (SMAD) were made and two classes of outliers were defined: the minor $\left(\mathrm{IC}_{50}\right.$ value between the median +1.65 and median + 3SMAD) and the major (greater than median + 3SMAD) (14).

Pyrosequencing and neuraminidase sequencing. Pyrosequencing was performed to determine the genotype at the $\mathrm{H} 275 \mathrm{Y}$ position in the viral neuraminidase gene in H1N1 viruses, using previously described methods (15). For those viruses identified statistically as outliers, the sequence of the neuraminidase gene was analyzed to identify changes that might be associated with reduced susceptibility.

Viral strains tested for amantadine susceptibility. The ion channel region of M2 was pyrosequenced to identify amantadine resistance causing mutations in 45 influenza A strain isolates between 2005 and 2008: 33 influenza $\mathrm{A}(\mathrm{H} 3 \mathrm{~N} 2)$ and 12 influenza $\mathrm{A}(\mathrm{H} 1 \mathrm{~N} 1)$ viruses.

Written informed consent and explicit ethical approval were not sought as this study was an observational undertaking as part of routine virological surveillance (anonymously, without identification of patients), as established in the terms of reference for World Health Organization National Influenza Centers. This is the basis of World Health Organization surveillance in more than 130 countries

\section{RESULTS}

\section{Seasonal surveillance}

During the period 2005-2008, as sampling efforts were constant throughout the year, influenza viruses were observed circulating from April to November in different regions; intense activity
FIGURE 1. Percentage of influenza A and B viruses from total samples studied detected by national network by month (January to November), ${ }^{a}$ Argentina, 2005-2008

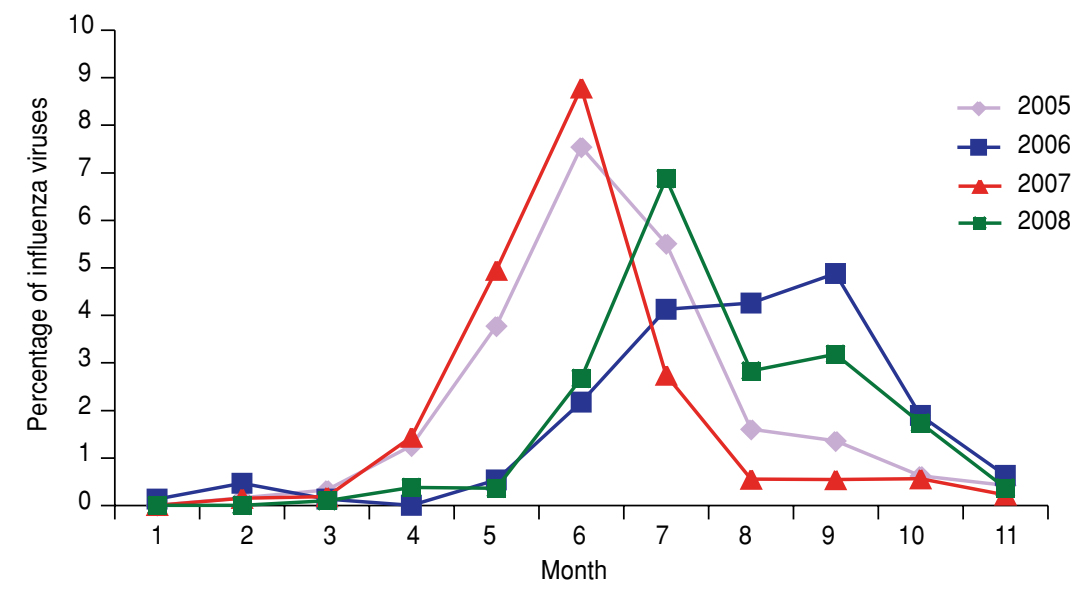

a Data for December not available. occurred in May and July, with the exception of the year 2006 when activity peaked between July and September. This behavior was demonstrated by the percentage of influenza-positive laboratory diagnostics reported from January to November (Figure 1).

The total number of samples studied by the national network during that period, the influenza-positive specimens received at the National Influenza Center, and the number of strains recovered in Madin-Darby canine kidney cells by type and subtype are shown in Table 2 . The average rate of virus isolation in tissue culture between 2005 and 2008 was $58.8 \%$.

\section{Subtyping and antigenic characterization}

Influenza A H3 and B virus circulation was detected throughout the study period, but influenza A H1 strains were detected only during 2006 and 2008. The circulating strains and the corresponding vaccine strains recommended for each influenza season are compared in Table 3.

\section{Prevalence of amantadine-resistant strains}

From 45 strains studied, including 33 $\mathrm{A}(\mathrm{H} 3 \mathrm{~N} 2)$ and $12 \mathrm{~A}(\mathrm{H} 1 \mathrm{~N} 1), 29 \mathrm{~A}(\mathrm{H} 3 \mathrm{~N} 2)$ $(87.8 \%)$ isolates were amantadine and rimantadine resistant. All $\mathrm{A}(\mathrm{H} 1 \mathrm{~N} 1)$ viruses tested retained sensitivity to these drugs (Table 4). All the amantadineresistant $\mathrm{A}(\mathrm{H} 3 \mathrm{~N} 2)$ isolates had an amino acid change from serine to asparagine at position $31(\mathrm{~S} 31 \mathrm{~N})$ in the M2 protein, as determined by pyrosequencing. Amantadine-resistant strains were first detected in Argentina in 2006 and were still circulating with high prevalence (100.0\%) until 2008.

\section{Susceptibility to neuraminidase inhibitors}

A total of 113 viruses isolated during the period 2005-2008 were evaluated:
TABLE 2. Samples studied by national network, samples received at National Influenza Center by type, and isolates recovered in MDCK cells by type and subtype, Argentina, 2005-2008

\begin{tabular}{|c|c|c|c|c|c|c|c|}
\hline \multirow[b]{2}{*}{ Year } & \multirow{2}{*}{$\begin{array}{c}\text { Samples } \\
\text { studied by NN }\end{array}$} & \multicolumn{2}{|c|}{$\begin{array}{c}\text { Samples received at } \\
\text { National Influenza Center }\end{array}$} & \multicolumn{4}{|c|}{ Isolates in MDCK } \\
\hline & & A & B & $\mathrm{H} 1$ & H3 & B Yam & B Vic \\
\hline 2005 & 29019 & 779 & 115 & 0 & 374 & 6 & 43 \\
\hline 2006 & 28921 & 560 & 156 & 259 & 31 & 28 & 51 \\
\hline 2007 & 30845 & 953 & 33 & 0 & 199 & 2 & 2 \\
\hline 2008 & 24017 & 370 & 275 & 219 & 5 & 208 & 2 \\
\hline Total & 112802 & 2662 & 579 & 478 & 609 & 244 & 98 \\
\hline
\end{tabular}

Note: MDCK: Madin-Darby canine kidney, NN: national network, B Yam: B Yamagata lineage, B Vic: B Victoria lineage. 
TABLE 3. Comparison between circulating strains and corresponding vaccine strains recommended by World Health Organization for each influenza season, Argentina, 2005-2008

\begin{tabular}{lll}
\hline Year & \multicolumn{1}{c}{ Circulating strain } & \multicolumn{1}{c}{ Vaccine strain } \\
\hline 2005 & A/California/07/04 (H3N2) & A/Wellington/1/04 (H3N2) \\
& B/Shangai/361/02 & A/New Caledonia/20/99 (H1N1) \\
& B/Hong Kong/330/01 & B/Shangai/361/02 \\
2006 & A/New Caledonia/20/99 (H1N1) & A/California/7/04 (H3N2) \\
& A/New York/55/04 (H3N2) & A/New Caledonia/20/99 (H1N1) \\
& B/Shangai/361/02 & B/Malaysia/2506/04 \\
& B/Malaysia/2506/04 & \\
2007 & A/Wisconsin/67/05 (H3N2) & A/Wisconsin/67/05 (H3N2) \\
& A/Brisbane/10/07 (H3N2) & A/New Caledonia/20/99 (H1N1) \\
& B/Shanghai/361/02 & B/Malaysia/2506/04 \\
& B/Hong Kong/330/01 & \\
& A/Solomon Islands/3/2006 (H1N1) & A/Solomon Islands/3/2006 (H1N1) \\
& B/Florida/4/2006 & A/Brisbane/10/2007 (H3N2) \\
& & B/Florida/4/2006 \\
\hline
\end{tabular}

TABLE 4. Number of resistant isolates per number of influenza $A$ viruses studied for amantadine resistance, Argentina, 2005-2008

\begin{tabular}{cccccr}
\hline & \multicolumn{3}{c}{ Resistant isolates/total isolates } \\
\cline { 2 - 3 } & \multicolumn{2}{c}{ H1N1 } & & \multicolumn{2}{c}{ H3N2 } \\
\cline { 2 - 3 } \cline { 5 - 6 } Year & Number & $\%$ & & Number & $\%$ \\
\hline 2005 & 0 & $\ldots$ & & $0 / 4$ & 0.0 \\
2006 & $0 / 4$ & 0.0 & & $4 / 4$ & 100.0 \\
2007 & 0 & $\ldots$ & & $24 / 24$ & 100.0 \\
2008 & $0 / 8$ & 0.0 & & $1 / 1$ & 100.0 \\
Total & $0 / 12$ & 0.0 & & $29 / 33$ & 87.8 \\
\hline
\end{tabular}

Note: .... not applicable.

46 influenza $\mathrm{B}, 35 \mathrm{~A}(\mathrm{H} 1 \mathrm{~N} 1)$, and 32 $\mathrm{A}(\mathrm{H} 3 \mathrm{~N} 2)$. Mean $\mathrm{IC}_{50}$ values for oseltamivir carboxylate and zanamivir by year, influenza type, and subtype are shown in Table 5. While there was some variability from year to year, for A(H3N2) and influenza $\mathrm{B}$ there was no trend toward increasing values; overall, values decreased in the third and fourth years of the period, respectively, when the largest number was studied.

\section{Influenza $\mathrm{A}(\mathrm{H} 1 \mathrm{~N} 1)$ viruses}

Of 35 N1-carrying viruses, 12 (34.3\%) isolated during the 2008 season demonstrated oseltamivir carboxylate $\mathrm{IC}_{50}$ values greater than the median + 3SMAD with normal $\mathrm{IC}_{50}$ values to zanamivir, while the remaining $23(65.7 \%)$ retained sensitivity to both antiviral drugs. The H275Y mutation, well known to confer a high-level resistance to oseltamivir, was confirmed by pyrosequencing in all the major outliers to oseltamivir carboxylate. There was no indication that any of these patients had received antiviral treatment before specimen collection.

\section{Influenza $\mathrm{A}(\mathrm{H} 3 \mathrm{~N} 2)$ viruses}

All influenza $\mathrm{A}(\mathrm{H} 3 \mathrm{~N} 2)$ viruses evaluated were sensitive to zanamivir and oseltamivir carboxylate. $\mathrm{IC}_{50}$ values were comparable to those from $\mathrm{A}(\mathrm{H} 3 \mathrm{~N} 2)$ viruses circulating in Europe in the same time frame (16).

\section{Influenza B viruses}

Of 46 influenza B isolates tested, 4 $(8.6 \%)$ demonstrated reduced susceptibility to oseltamivir carboxylate, with $\mathrm{IC}_{50}$ values above the minor outlier definition. A further two influenza B isolates were minor outliers to zanamivir $(4.3 \%)$. Because the results were inconclusive, this phenotypic assay was complemented with the full neuraminidase gene sequencing of the viruses identified statistically as outliers with the required reduction in the $\mathrm{IC}_{50}$ value. A sequencing assay showed that none of these viruses contained neuraminidase substitutions identified with previously described mutations known to confer resistance (17).

\section{DISCUSSION}

The recurring emergence of influenza virus strains resistant to available antiviral medications has become a global health concern, especially in light of the potential for a new influenza virus pandemic.

This study reports results of virological and drug susceptibility surveillance among selected influenza $\mathrm{A}(\mathrm{H} 1 \mathrm{~N} 1)$, $\mathrm{A}(\mathrm{H} 3 \mathrm{~N} 2)$, and $\mathrm{B}$ viruses isolated in Argentina during the period 2005-2008 in which all types (A and B) and human subtypes of influenza viruses circulated in the human population throughout the study period.

Most influenza A H3 strains characterized for each influenza season had

TABLE 5. Analysis of $\mathrm{IC}_{50}$ values obtained for oseltamivir and zanamivir antiviral drugs for different influenza types and subtypes, Argentina, 2005-2008

\begin{tabular}{|c|c|c|c|c|c|c|c|c|c|c|c|c|}
\hline \multirow[b]{3}{*}{ Year } & \multicolumn{4}{|c|}{$\mathrm{A}(\mathrm{H} 1 \mathrm{~N} 1)$} & \multicolumn{4}{|c|}{$\mathrm{A}(\mathrm{H} 3 \mathrm{~N} 2)$} & \multicolumn{4}{|c|}{ B } \\
\hline & \multicolumn{2}{|c|}{ Oseltamivir } & \multicolumn{2}{|c|}{ Zanamivir } & \multicolumn{2}{|c|}{ Oseltamivir } & \multicolumn{2}{|c|}{ Zanamivir } & \multicolumn{2}{|c|}{ Oseltamivir } & \multicolumn{2}{|c|}{ Zanamivir } \\
\hline & $\begin{array}{c}\text { Mean } \mathrm{IC}_{50} \\
\mathrm{nM}\end{array}$ & $\begin{array}{l}\text { No. of } \\
\text { isolates }\end{array}$ & $\begin{array}{c}\text { Mean } \\
\mathrm{IC}_{50} \\
\mathrm{nM}\end{array}$ & $\begin{array}{l}\text { No. of } \\
\text { isolates }\end{array}$ & $\begin{array}{c}\text { Mean } \\
\mathrm{IC}_{50} \\
\mathrm{nM}\end{array}$ & $\begin{array}{l}\text { No. of } \\
\text { isolates }\end{array}$ & $\begin{array}{c}\text { Mean } \\
\mathrm{IC}_{50} \\
\mathrm{nM}\end{array}$ & $\begin{array}{l}\text { No. of } \\
\text { isolates }\end{array}$ & $\begin{array}{c}\text { Mean } \\
I_{50} \\
\mathrm{nM}\end{array}$ & $\begin{array}{c}\text { No. of } \\
\text { isolates }\end{array}$ & $\begin{array}{c}\text { Mean } \\
I_{50} \\
\mathrm{nM}\end{array}$ & $\begin{array}{l}\text { No. of } \\
\text { isolates }\end{array}$ \\
\hline 2005 & 0 & 0 & 0 & 0 & 0.14 & 4 & 0.36 & 4 & 20.98 & 6 & 2.32 & 6 \\
\hline 2006 & 1.43 & 4 & 1.31 & 4 & 0.71 & 3 & 1.18 & 3 & 48.01 & 5 & 6.84 & 5 \\
\hline 2007 & 0 & 0 & 0 & 0 & 0.53 & 24 & 0.5 & 24 & 0 & 0 & 0 & 0 \\
\hline 2008 & $2.18 / 573.5^{a}$ & $19 / 12^{b}$ & 1.36 & 31 & 0.15 & 1 & 0.22 & 1 & 33.23 & 35 & 6.62 & 35 \\
\hline Total & $\ldots$ & 35 & $\ldots$ & 35 & $\ldots$ & 32 & $\ldots$ & 32 & $\ldots$ & 46 & $\ldots$ & 46 \\
\hline
\end{tabular}

Note: $\mathrm{IC}_{50}$ : concentration that provides $50 \%$ inhibition, ...: not applicable.

${ }^{a}$ Mean $\mathrm{IC}_{50}$ value for sensitive strains/mean $\mathrm{IC}_{50}$ value for resistant strains.

b 19 sensitive isolates $/ 12$ resistant isolates. 
antigenic characteristics similar to the vaccine strain. The strain A/California/07/2004 is an antigenic variant of the $\mathrm{H} 3$ vaccine component $\mathrm{A} /$ Wellington/1/04. A/New York/55/2004, the H3 strain that circulated mostly in 2006, was used by most manufacturers for 2006 vaccine production. The strain $\mathrm{A} / \mathrm{Wis}-$ consin/67/2005 was an antigenic variant of A/California/07/2004 and was recommended by the World Health Organization as the $\mathrm{H} 3$ component for the 2007 southern hemisphere formulation. A/Brisbane/10/2007-like virus was the recommended influenza $\mathrm{A}(\mathrm{H} 3 \mathrm{~N} 2)$ component for the 2008 southern hemisphere formulation.

A high incidence of amantadine-resistant influenza $\mathrm{A}(\mathrm{H} 3 \mathrm{~N} 2)$ viruses possessing the mutation $\mathrm{S} 31 \mathrm{~N}$ has been detected in Argentina since 2006 (9) and its circulation was still detected in 2008. These resistant strains are transmissible and able to cause disease $(12,18)$.

In 2006, influenza A H1 circulating and vaccine strains were antigenically similar, but in 2008 two distinct variants were isolated and a small proportion of the 2008 vaccine reference strain A/ Solomon Islands/3/06 circulated. A/ Brisbane/59/2007 is a more recent genetic antigenic variant that evolved from A/Solomon Islands/03/2006.

In 2008, influenza activity was moderate in Argentina and the season was notable for an unprecedented increase in oseltamivir resistance due to the muta-

FIGURE 2. Influenza A and B viruses detected by national network by month (January to November), ${ }^{\text {a Argentina, 2005-2008 }}$

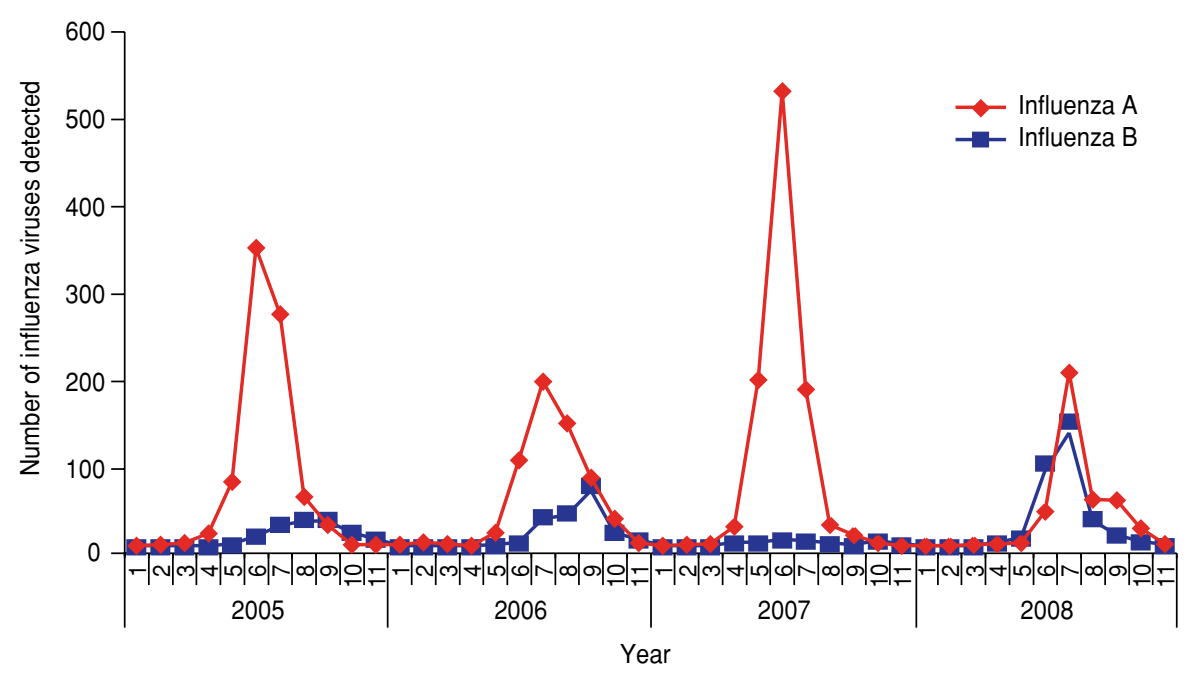

a Data for December not available. tion $\mathrm{H} 275 \mathrm{Y}$ in the neuraminidase protein of influenza $\mathrm{A}(\mathrm{H} 1 \mathrm{~N} 1)$ viruses $(34 \%)$. These results are consistent with those described by global monitoring of influenza strains circulating in the world (19). Phylogenetic analysis of the $\mathrm{H} 1$ gene showed that Argentinean resistant and sensitive viruses tested were grouped together in a previously described subclade called 2B (20), including the recent vaccine strain A/Brisbane/59/2007. The mutation conferring resistance had no impact on zanamivir susceptibility; thus, in cases of oseltamivir-resistant influenza virus infection, zanamivir would be a more appropriate treatment than oseltamivir.

The circulation of influenza B viruses was detected in 2005, 2006, and 2008 (Figure 2). They belonged to two lineages, Yamagata and Victoria, and they were antigenically related to the vaccine strain in 2006 and 2008.

According to the mean $\mathrm{IC}_{50}$ values shown in Table 5, relative susceptibility was consistent with previously published results, with the influenza $\mathrm{A}(\mathrm{H} 1 \mathrm{~N} 1)$ and $\mathrm{B}$ viruses being more sensitive to zanamivir and the influenza $\mathrm{A}(\mathrm{H} 3 \mathrm{~N} 2)$ viruses being more sensitive to oseltamivir (21). Influenza A viruses were more sensitive to both neuraminidase inhibitors than the influenza B viruses. These findings are in accord with reports of influenza drug susceptibility in previous years $(21,22)$. A trend of increasing $\mathrm{IC}_{50}$ values in influenza $\mathrm{B}$

isolates has been observed in surveillance studies, and reduced clinical efficacy of oseltamivir in particular has been observed in clinical studies $(17,18$, 23, 24). For influenza $\mathrm{A}(\mathrm{H} 3 \mathrm{~N} 2)$ isolates, no extreme outliers were identified. The influenza B isolates ranged as outlier viruses could not be considered as resistant viruses if one considers the limited reduction in neuraminidase sensitivity to the inhibitors and the existence of mutations in neuraminidase that did not belong to those currently associated with influenza resistance to zanamivir and oseltamivir inhibitors (15).

Ezequiel Palma of Roche Argentina pointed out that during the period studied, prescriptions of oseltamivir in Argentina were low, between 600 and 1000 units per year, which represents 0.02-0.03 per 1000 population (personal communication, 3 February 2009). According to available information, the oseltamivir-resistant viruses analyzed in this study were recovered from patients less than 7 years old. There is no information that any of these isolates were obtained from persons who were treated or were in close contact with another individual who was treated with antiviral drugs. Therefore, oseltamivir resistance is unlikely to be related to antiviral medication of patients, as in other countries, where there are few instances of resistant viruses being isolated from persons who have been treated or have been in close contact with another individual who was treated with oseltamivir $(25,26)$.

During the 2009 influenza A(H1N1) pandemic, oseltamivir was extensively used for treatment and prophylaxis. A total of 319 cases infected with oseltamivir-resistant influenza viruses have been recognized globally from more than 20000 influenza samples tested (27). So far, the main association for the emergence of cases of oseltamivir-resistant influenza A(H1N1) 2009 virus was receiving antiviral therapy and having drug-induced immunosuppression or a hematologic disorder (28).

The limitations of this work include a lack of corresponding epidemiological data supporting the virological results and a lack of selection of a specific population to perform the study. The influenza virus surveillance and antiviral resistance studies can lead to better decisions in health policies and help in medical treatment of severe cases. Monitoring the 
patterns of influenza epidemics is essential for the yearly planning of prevention and response activities, for identifying groups at high risk of complications, and for estimating the health and economic burden of influenza. This report highlights the importance of performing the antigenic and genetic surveillance of the influenza viruses required by the World Health Organization to make annual recommendations on the composition of influenza vaccines for the northern and southern hemispheres. In addition, data obtained at the National Influenza Cen- ter contribute to the global influenza surveillance, which serves as the primary global alert mechanism for detecting the emergence of novel influenza viruses that could cause a public health alert.

Acknowledgments. The authors are grateful to collaborators from the Health Protection Agency (Colindale, London) and the World Health Organization Collaborating Centre for Reference and Research on Influenza (Mill Hill, London) in the United Kingdom for providing the opportunity to be trained in pheno-

\section{REFERENCES}

1. Molinari A, Ortega-Sanchez I, Messonnier ML, Thompson WW, Wortley PM, Weintraub E, et al. The annual impact of seasonal influenza in the US: measuring disease burden and costs. Vaccine. 2007;25(27):5086-96.

2. Hilleman MR. Realities and enigmas of human viral influenza: pathogenesis, epidemiology and control. Vaccine. 2002;20(2526):3068-87.

3. World Health Organization. Recommended composition of influenza virus vaccines for use in the 2008-2009 influenza season. Wkly Epidemiol Rec. 2008;83(9):81-7.

4. World Health Organization. Recommended composition of influenza virus vaccines for use in the 2009 southern hemisphere influenza season. Wkly Epidemiol Rec. 2008;83(41):36672.

5. Davies WL, Grunert RR, Haff RF, McGahen JW, Neumayer EM, Paulshock M, et al. Antiviral activity of 1-adamantanamine (amantadine). Science. 1964;144:862-3.

6. Hay AJ. The action of adamantanamines against influenza A viruses: inhibition of the M2 ion channel protein. Semin Virol. 1992;3:21-30.

7. von Itzstein M, Wu WY, Kok GB, Pegg MS, Dyason JC, Jin B, et al. Rational design of potent sialidase-based inhibitors of influenza virus replication. Nature. 1993;363(6428): 418-23.

8. Bright RA, Medina MJ, $\mathrm{Xu} X$, Perez-Oronoz $\mathrm{G}$, Wallis TR, Davis $\mathrm{XM}$, et al. Incidence of adamantane resistance among influenza $\mathrm{A}(\mathrm{H} 3 \mathrm{~N} 2)$ viruses isolated worldwide from 1994 to 2005: a cause for concern. Lancet. 2005;366(9492):1175-81.

9. Pontoriero A, Baumeister E, Campos AM, Moreno A, Cadario ME, Savy V. Surveillance of adamantane resistance among influenza A H3 viruses isolated in Argentina between 2001 and 2007. Rev Argent Microbiol. 2008;40(3):180-4.

10. Meijer A, Lackenby A, Hungnes O, Lina B, van der Werf S, Schweiger B, et al. Oseltamivir-resistant influenza virus A (H1N1), Europe, 2007-08 season. Emerg Infect Dis. 2009;15(4):552-60. Available from: http:// www.nimr.mrc.ac.uk/documents/about/ interim_report_feb_2009.pdf Accessed 15 September 2011.

11. Kim CU, Lew W, Williams MA, Liu H, Zhang $\mathrm{L}$, Swaminathan S, et al. Influenza neuraminidase inhibitors possessing a novel hydrophobic interaction in the enzyme active site: design, synthesis and structural analysis of carbocyclic sialic acid analogues with potent anti-influenza activity. J Am Chem Soc. 1997;119:681-90.

12. Lackenby A, Hungnes O, Dudman SG, Meijer A, Paget WJ, Hay AJ, et al. Emergence of resistance to oseltamivir among influenza A(H1N1) viruses in Europe. Euro Surveill. 2008;13(5). Available from: http://www. eurosurveillance.org/images/dynamic/EE/ V13N05/art8026.pdf Accessed 5 February 2009.

13. Hay A, Daniels R, Lin Y, Zheng X, Gregory V, Hou $T$, et al. World Influenza Centre interim report, February 2009. London: WHO Influenza Centre; 2009. Available from: http:// www.nimr.mrc.ac.uk/documents/about/ interim_report_feb_2009.pdf Accessed 15 September 2011.

14. WHO Global Influenza Surveillance Network. Manual for the laboratory diagnosis and virological surveillance of influenza. Geneva: WHO; 2011. Available from: http://whqlibdoc.who.int/publica tions/2011/9789241548090_eng.pdf Accessed 16 September 2011.

15. Lackenby A, Democratis J, Siqueira MM, Zambon MC. Rapid quantitation of neuraminidase inhibitor drug resistance in influenza virus quasispecies. Antivir Ther. 2008;13(6):809-20.

16. Jonges $\mathrm{M}$, van der Lubben IM, Dijkstra $\mathrm{F}$, Verhoef L, Koopmans M, Meijer A. Dynamics of antiviral-resistant influenza viruses in the Netherlands, 2005-2008. Antiviral Res. 2009;83(3):290-7.

17. Sugaya N, Mitamura K, Yamazaki M, Tamura D, Ichikawa M, Kimura K, et al. Lower clinical effectiveness of oseltamivir against influenza B contrasted with influenza A infection in children. Clin Infect Dis. 2007;44(2):197-202.

18. Kawai N, Ikematsu H, Iwaki N, Kawashima T, Maeda T, Mitsuoka S, et al. Longer virus typic and genomic antiviral susceptibility testing and sharing sequence data. The authors thank the participating laboratories in the national network for their submission of clinical samples and the Servicio de Cultivo de Tejidos at the Instituto Nacional de Enfermedades Infecciosas Administración Nacional de Laboratorios e Institutos de Salud (INEI ANLIS) “Dr. Carlos G. Malbrán" for supplying the Madin-Darby canine kidney cells and media. This research was financially supported by INEI ANLIS “Dr. Carlos G. Malbrán." shedding in influenza B than in influenza A among outpatients treated with oseltamivir. J Infect. 2007;55(3):267-72.

19. World Health Organization. Influenza A (H1N1) viruses resistant to oseltamivir-last quarter 2007 to 5 May 2008. Geneva: WHO; 2008. Available from: http://www.who.int/ influenza/patient_care/antivirals/oseltami vir_summary/en/ Accessed 13 November 2011.

20. Hay A, Daniels R, Lin Y, Zheng X, Gregory $\mathrm{V}$, Bennett $\mathrm{M}$, et al. Characteristics of human influenza AH1N1, AH3N2 and B viruses isolated September 2007 to February 2008. London: WHO Influenza Centre; 2008. Available from: http://www.nimr.mrc.ac.uk/wic/ report/documents/interin_report_mar_2008. pdf Accessed 26 September 2008.

21. McKimm-Breschkin J, Trivedi T, Hampson A, Hay A, Klimov A, Tashiro M, et al. Neuraminidase sequence analysis and susceptibilities of influenza virus clinical isolates to zanamivir and oseltamivir. Antimicrob Agents Chemother. 2003;47(7):2264-72.

22. Mungall BA, Xu X, Klimov A. Surveillance of influenza isolates for susceptibility to neuraminidase inhibitors during the 2000-2002 influenza seasons. Virus Res. 2004;103(12):195-7.

23. Sheu TG, Deyde VM, Okomo-Adhiambo M, Garten RJ, Xu X, Bright RA, et al. Surveillance for neuraminidase inhibitor resistance among human influenza A and B viruses circulating worldwide from 2004 to 2008. Antimicrob Agents Chemother. 2008;52(9):3284-92.

24. Lackenby A, Baldevarona J, Democratis J, Wigmore $\mathrm{H}$, Andrews N, Ellis J, et al. Decreasing sensitivity of influenza $\mathrm{B}$ viruses to neuraminidase inhibitors. In: Katz JM, ed. Options for the control of influenza IV. London: International Medical Press Ltd.; 2008. P. 238

25. Cané A, Casanueva E, Iolster T, Sticco N, Richards L, Sosa P, et al. First isolation of a oseltamivir-resistant influenza A (H1N1) strain in Argentina. Pediatr Infect Dis J. 2010;29(4):384.

26. Valinotto LE, Diez RA, Barrero PR, Farías JA, López EL, Mistchenko AS. Emergence 
of intratreatment resistance to oseltamivir in pandemic influenza A H1N1 2009 virus. Antivir Ther. 2010;15(6):923-7.

27. World Health Organization. Weekly update on oseltamivir resistance to influenza H1N1 (2009) viruses. Geneva: WHO; 2009. Available from: http://www.who.int/csr/disease/ influenza/2011_01_12_weekly_web_update_ oseltamivir_resistance.pdf Accessed 14 January 2011.

28. Meijer A, Jonges $\mathrm{M}$, Abbink F, Ang $\mathrm{W}$, van Beek J, Beersma M, et al. Oseltamivir-resistant pandemic A(H1N1) 2009 influenza viruses detected through enhanced surveillance in the Netherlands, 2009-2010. Antiviral Res. 2011;92(1):81-9.

Manuscript received on 5 April 2011. Revised version accepted for publication on 31 October 2011.

RESUMEN Objetivo. Describir las características virológicas de las cepas de virus de la gripe que circulaban en la Argentina entre el 2005 y el 2008, y evaluar la prevalencia de la resistencia a los antivíricos.

Vigilancia virológica y resistencia a los antivíricos del virus de la gripe humana en la Argentina, 2005-2008

Palabras clave
Métodos. Según su diseminación geográfica y su prevalencia, se seleccionaron aislados de gripe A y B cultivados en células renales caninas de Madin-Darby después de su caracterización antigénica y genómica, y se analizó su resistencia a los antivíricos mediante análisis enzimático y pirosecuenciación. La sensibilidad a la amantadina se evaluó por pirosecuenciación para los marcadores conocidos de resistencia en 45 cepas de gripe A. La sensibilidad al oseltamivir y al zanamivir se evaluó mediante análisis enzimático de 67 cepas de gripe A y 46 cepas de gripe B, algunas de las cuales se analizaron en mayor profundidad mediante la secuenciación del gen de la neuraminidasa.

Resultados. Se observó resistencia a la amantadina solo en las cepas de gripe A (H3N2) (29/33); todas ellas tenían la mutación S31N en su secuencia de M2. Se observó resistencia al oseltamivir en $12(34,3 \%)$ de las 35 cepas de gripe A (H1N1) aisladas en el 2008; todas ellas tenían la mutación H275Y en su secuencia de neuraminidasa. Todos estos virus conservaron su sensibilidad al zanamivir.

Conclusiones. En este estudio se describe una incidencia elevada del virus de la gripe A (H3N2) resistente a la amantadina desde el 2006 y un aumento sin precedentes de la resistencia al oseltamivir detectada solo en los virus de la gripe A (H1N1) aislados en el 2008. Los virus de la gripe A y B fueron más sensibles al oseltamivir que al zanamivir y los virus de la gripe A fueron más sensibles a ambos inhibidores de la neuraminidasa que los virus de la gripe B. Los datos nacionales generados y analizados en este estudio pueden ayudar a aumentar los conocimientos acerca de la resistencia a los fármacos antivíricos dirigidos contra el virus de la gripe, lo que es un motivo de preocupación mundial.

Influenza humana; virus de la influenza A; farmacorresistencia viral; agentes antivirales; Argentina. 